are distinctly subject to climatic causes, and the explanation given in my former article, which attributes them to irritability of temper consequent on long-continued heat and moisture, is the best I can put forward.

When the birth statistics are analyzed with reference to the annual period, results equally striking and curious are brought out. The numbers registered, when tabulated month by month, corrected for the causes of error mentioned at the commencement of this article, and thrown into the form of average rates per thousand per annum, give the following table, in which also the monthly ratios, which are for nine years only, have been slightly altered sn as to make the annual mean equal to that already found for ten years:-

\begin{tabular}{|c|c|c|c|c|c|c|c|c|}
\hline \multicolumn{2}{|l|}{ Month. } & \multicolumn{2}{|l|}{ Males. } & \multicolumn{2}{|c|}{ Females. } & Total. & \multicolumn{2}{|c|}{$\begin{array}{l}\text { Number of } \\
\text { Males to } \\
\text { xoo Femal }\end{array}$} \\
\hline January & $\ldots$ & $22 \cdot 67$ & $\cdots$ & $21 \cdot 92$ & .. & $44: 59$ & $\ldots$ & $103 \cdot 42$ \\
\hline February & $\ldots$ & $22 \cdot 3 \mathrm{I}$ & $\ldots$ & $2 \mathrm{I} \cdot 53$ & $\cdots$ & 43.84 & $\cdots$ & 103.67 \\
\hline March & $\ldots$ & $20 \% 72$ & $\ldots$ & $19^{\circ} 95$ & $\cdots$ & $40 \cdot 67$ & $\ldots$ & 10 \\
\hline April & ... & $20: 17$ & $\ldots$ & 30 & $\ldots$ & 39.47 & $\ldots$ & 4.51 \\
\hline May & $\cdots$ & $18 \cdot 46$ & $\cdots$ & 17 & $\cdots$ & 36.11 & $\cdots$ & 104.65 \\
\hline Jur & $\ldots$ & $18 \cdot 12$ & $\ldots$ & I 7 & $\cdots$ & $35^{\circ} 43$ & $\ldots$ & 104.74 \\
\hline fuly & $\ldots$ & $20 \cdot 80$ & $\ldots$ & $19 \% 70$ & $\cdots$ & 40 & $\cdots$ & 59 \\
\hline August & $\ldots$ & $25: 8 \mathrm{I}$ & $\ldots$ & 24.72 & $\cdots$ & 50 & $\cdots$ & $\mathrm{IO}_{4} 4 \mathrm{I}$ \\
\hline Septembe & & $28 \cdot 85$ & $\ldots$ & $27 \cdot 86$ & $\cdots$ & $56 \cdot 71$ & $\ldots$ & IO3.55 \\
\hline Octo & $\ldots$ & $28 \cdot 30$ & $\ldots$ & $274 \mathrm{I}$ & $\cdots$ & $557 \mathrm{I}$ & $\cdots$ & 103.25 \\
\hline Nov & $r \ldots$ & $25 \cdot 89$ & $\cdots$ & $25 \cdot 15$ & $\cdots$ & $5 \mathrm{I}^{\circ} \mathrm{O} 4$ & $\cdots$ & IO2.94 \\
\hline December & $r \ldots$ & $25^{\circ} 3^{6}$ & $\cdots$ & $24 \cdot 88$ & $\cdots$ & $50 \cdot 24$ & . & $1015^{2}$ \\
\hline Year & & & $\cdots$ & $22 \cdot 28$ & & $45^{\circ} 40$ & & 1 \\
\hline
\end{tabular}

From the existence of the Holi festival among the Hindus, and of similar spring festivals, accompanied with lascivious songs and dances, among many barbarous tribes, as well as from the traces of such festivals still surviving in Europe, and the hints given by classical writers regarding the nature of certain annual religious mysteries performed by the early Greeks and Romans, anthropologists have thought that possibly, during prehistoric times, the human species, like the lower animals in a state of nature, had an annual pairing-time. If any traces of such a condition still survive, we may with some confidence look for them in India, where a large number of the poorer classes are chronically on the verge of starvation, and the different seasons are sufficiently marked in character to affect people differently both in body and in mind. The birth-rates in the above table, represented by Fig. 17 in the diagram, exhibit a most distinct annual variation, smoother and more uniform in character than any of the mortality curves, and with a range equal to nearly 50 per cont. of the mean value. The minimum falls in June and the maximum in September,--dates which point to a maximum of conceptions in December, and a minimum in September. "The latter month is near the end of the long and depressing hot season, when malarial influences are rapidly increasing to a maximum, the food-supply of the year is nearly exhausted, and there is the greatest tendency to suicide. The births, as well as the deaths, therefore, show that at the end of the rains the vitality and energy of the people have reached low-water mark.

In December, on the other hand, not only is the salubrity of the country greatly increased, as shown by the rapid diminution of nearly every cause of death, but food is again cheap and abundant. The crops of millet, on which the poorer classes live, are sown in July and reaped in November. During Necember and the latter half of November they are threshed out, and then is the season for paying the village functionaries and labourers their share of the produce. Consequently food is more abundant at this time of the year than at any other, and as a result of these conditions we find a large number of births the following September and October.

It thus appears that among the poorest of the population there is probably still a more or less distinct annual reproductive season, but instead of being determined by the returning warmth of spring, as must have been the case in prehistoric Europe, it follows the annual return of healthy conditions with abundant food-supply. That the Holi festival occurs in spring, instead of in December, is perhaps to be accounted for as a survival from a time when the ancestors of the Hindus lived in a colder climate.

In the last column of the table are given the monthly values of the ratio of males to females at birth. This appears to be subject to a small but distinct annual variation, with a maximum in July, and a minimum in December; but whether this is a remote and obscure physiological effect of the annual march of the seasons, or only a chance arithmetical result, I cannot say.
Allahabad, February 8.
S. A. HILL.

\section{ON THE ORBITS OF AEROLITES. 1}

MY studies have led me to the following three M propositions:

I. The meteorites which we have in our cabinets and which were seen to fall were originally (as a class, and with a very small number of exceptions), moving about the sun in orbits that had inclinations less than $90^{\circ}$; that is, their motions were direct, not retrograde.

2. The reason why we have only this class of stones in our collections is not one wholly or even mainly dependent on the habits of men; nor on the times when men are out of doors; nor on the places where men live; nor on any other principle of selection acting at or after the arrival of the stones at the ground. Either the stones which are moving in the solar system across the earth's orbit move in general in direct orbits; or else for some reason the stones which move in retrograde orbits do not in general come through the air to the ground in solid form.

3. The perihelion distances of nearly all the orbits in which these stones moved were not less than $0^{\prime} 5$ nor more than $I^{\circ} \mathrm{O}$, the earth's radius vector being unity.

The first and thirds propositions are limited strictly by their terms to the meteorites from stone-falls actually witnessed, and also represented by specimens in some one or more of existing collections. The investigations that have led to them have been limited to the same stonefalls. This is not because any line of separation is sus. pected to exist astronomically between the stone-furnishing and detonating meteors, or even between them and the shooting stars, but because, for manifest reasons, any facts established about these stones have a greater value than similar facts about meteors from which no stones have been secured.

About 265 observed falls are represented by specimens in existing collections. The history of these falls I have searched out with no little pains, so far as the material for such history could be found in books accessible to me. Every direct statement and every indirect indication which I have obtained about the paths of these meteors through the air have been carefully considered, and their meaning and value duly estimated The determination of the path of a stone-furnishing meteor through the air is greatly aided by the fact that we know at once one point of the trajectory, viz.: the point where the stone strikes the ground. To this fact may usually be added another, viz: that some of the observations are by persons near the place of fall, and hence their statements of direction, so far as we may trust them, have peculiar significance. In individual cases it will be found that not much reliance can be placed upon the asserted direction of the meteor's motion. But when the results are all

I "Upon the relation which the former Orbits of those Meteorites that are H. A. Newton. (From the American Fournal of Science, July i 888.) 
collated there is such a general agreement in support of the first and third propositions set forth above that I am very confident that they are true.

The orbit of a meteoroid about the sun is wholly given when we know these three things, the time when it enters the air, the direction of its motion, and the velocity. The velocity cannot be easily measured directly. But the connection between meteors and comets will be assumed as fully proven. The velocity of the meteoroids (neglecting the increase due to the earth's attraction), ought then to be that of the comets, at the same distance from the sun. The greatest cometary velocity at the distance unity is $\sqrt{2}$, the earth's velocity being unity. The smallest velocity for any known comet is that of Encke's comet, which at the earth's mean distance from the sun is I 244 . It seems safe, therefore, to assume that the meteorites we are considering had velocities relative to the sun not greater than $\mathrm{I}^{\prime} 4 \mathrm{I} 4$, nor less than $\mathrm{I}^{\prime} 244$.

The direction of a meteor's motion through the air is to be determined solely by the evidence of observers of the stone-fall. This evidence needs to be carefully collated, especially when statements apparently conflict. A judicial temper of mind must be preserved in estimating the meaning of the statements, lest the evidence be twisted to the support of some preconceived notion. Knowing the danger, I have tried to keep my own mind free from bias.

We need not know the exact day, but we must know the time of day of the stone-fall, else the direction through the air cannot be used. This throws out about one-fifth of the total number of falls named above,there being no statement of the time of day of the fall attainable. There are left 2 Io different cases available for use. For 94 of these there is no reliable statement of the direction of the motion of the meteor. We know only the day and the hour. Even this, however, is of some value, since we know that the meteor must have been moving downward at the place of fall; that is, from some point of the heavens then above its horizon. For 116 stone-falls the direction of the motion of the meteor is more or less definitely inclicated by the statements of observers, or by the statements of those who have inquired into and reported the facts of the falls.

We may then divide the observed stone falls into three groups which will be separately considered: (a), II6 falls for which we have statements as to the direction of the path through the air ; (b), 94 falls of which we know the time of day; $(c), 50$ or more falls of which the history is too scanty to give the time of day.

There is frequent occasion to speak of two points on the celestial sphere for which the English langutge has no good names. These are the point from which a body is moving, and the point to which a body is moving. These two points are opposed to each other, as north is to south, east to west, zenith to nadir. The words quit and goal will be used to denote these two points. The earth's quit is that poicit of the ecliptic from which the earth is moving, the earth's goal that point to which the earth is moving; the one being about $90^{\circ}$ ahead of the sun in the ecliptic, the other $90^{\circ}$ behind it. A meteor's quit is that point of the heavens from which the meteor is moving ; its goal that point of the heavens to which it is moving. The motion may be that relative to the earth, in which case the foilut of the celestial sphere from which it is moving is the meteor's relative quit. Thus the relative quit of a mateor when it is entering the air must be above the horizon of the place of entrance, inasmuch as the meteor must be moving downward. If a meteoroid's motion be corrected for the earth's motion the direction of its absclute motion about the sun is obtained, and then the two points of the celestial sphere from which and to which the meteoroid is moving are its absolute quit and its absolute goal.

The observations have been treated graphically. They do not demand nor do they admit of greater accurazy in methods of discussion than can be used in graphic processes, and these processes have many advantag $₫ 5$ over numerical computations. A stereographic projection of two hemispheres was prepared and printed, upon which there were three sets of coordinate lines from three sets of poles. The thrce sets of points were the angles of triquadrantal triangles. Thus the lines were drawn to represent at intervals of $10^{\circ}$ the distances and directions from the poles P, P, S, E, and G, Q, (Fig. I). In the engraved figure these coordinate limes are omitted. The common diameter of the two bemispheres $E S E$ was made to represent the ecliptic, and the sun was placed at the centre or at the edge of one of the hemispheres. The points $\mathrm{P}$ would then be the poles of the ecliptic, and if $\mathrm{S}$ be the place of the sun the earth's quit will be $Q$, and the earth's gnal G.

To treat any single meteor a large celestial globe was first set for the time and place of the fall. Upon the globe the celestial latitude and longitude of the zenith and of the west-point were then measured. The day of the year gave the sun's longitude. The zenith and westpoint could then be marked upon the chart, after which it was easy to draw the curcles representing the meridian and the prime vertical. The stereo-graphic projection was peculiarly advantageous in this work as all circies are represented by circles, and angles are conserved in the projection. The effort was then made to mark upon the chart the meteor's relative quit as accurately as the observations permit, or rather to describc an area within which the quit was probably or certainly located

Some of the 116 meteorite quits have been heretofore fairly well determined by other persons, or they can be so determined. This is the case with the meteors of Agram, Weston, Orgeuil, Pultusk, lowa, Rochester, Estherville, Krahenberg, Khairpur, Vendome, etc. For other cases we are able by comparing the various statements of observers to locate approximately the relative quit. But for a considerable number of the falls we have to be content with the simile statement that the stones came from the north, or from the northeast, or from the southsoutheast, or from some other similarly defined direction. Wher this has been the case 1 have taken a point $20^{\circ}$ above the horizon in the direction indicated, and considering this as the centre of an area of considerable size within whic's the quit was probably locater!, have treated the point itself as the meteor's quit.

These observations of direction in some cases will be in error, or will be perverted in reporting, as every one who has tried to reconcile numerous accounts of a meteor has unpleasantly learned. But when the statements have come from pcrsons who saw the stones come down, they are usually of much more value than similar reports about ordinary meteors. In any case when the reports are single they must be taken for what they are worth. I have plotted them as given.

In several notable instances where there are full accounts 1 have not been able to accept the conclusions heretofore arrived at as to the direction of the meteor's path. Thus, I)r. Bowditch made the path of the Weston meteor to be from north to south and parallel to the horizon. I make it to have moved from a point N. $40^{\circ}$ $\mathrm{W}, 35^{\circ}$ high. The Cold-Bokkeveld meteor was described by Sir Thomas Maclear as moving from the west-northwest. It apparently moved in the opposite direction; that is, from the east-south-east. The l'Aigle meteor was described by $M$. Biot as moving from the south-southeast, whereas it is well nigh certain that it came from the north-west. In like manner the Stannern meteorite was assumed by von Schreibers to have come from the northnorth-west, whereas there are reasons of great weight for believing that it came from the opposite direction. I may add that these and other like changes are not made under any pressure or bias to prove my proposi- 
tions. In fact three of the four changes just named make the evidence for my conclusions weaker instead of stronger.

In the treatment of the observations several quantities have been neglected as not large enough to be comparable with the probable errors of the observations themselves. Thus the effect of the earth's attraction in changing the direction of motion, or what has been called the zenithal attraction of the quit, has been allowed for only in a general way. So the earth's quit and goal are treated as being exactly $90^{\circ}$ from the sun; or, in other words, the earth's orbit has been treated as a circle. In like manner the motion of the place of fall due to the earth's rotation on its axis has not been taken account of.

Having located upon the chart the meteor's relative quit we have next to construct its absolute quit. This evidently lies on the great circle joining the relative quit to $\mathrm{Q}$ (Fig. I), which, when the sun is at $\mathrm{S}$ is represented on the chart by a straight line through $Q$, together with its corresponding line through $\mathrm{G}$. When the absolute velocity of the meteroid in its motion about the sun is given, the place on this circle of the absolute quit can be determined by combining by the parallelogram of velocities the motions of the earth and of the meteoroid. The following table is an abstract of a larger one used in this reduction, and is constructed for the limiting velocities I'4 I 4 and I'244:-

Table showing the Distances from the Earth's Ouit to the Absolute Quit of a Meteoroid for Different Distances from the Earth's Quit to the Relative Quil of the Meteoroid.

Distance from $Q$ to relative quit. Distance from $Q$ to absolute quit,

\begin{tabular}{|c|c|}
\hline $30^{\circ}$ & $\begin{array}{c}v={ }^{\circ} \cdot 414 . \\
9^{\circ} \cdot 3\end{array}$ \\
\hline 60 & $22 \cdot 1$ \\
\hline 90 & $45^{\circ} \mathrm{O}$ \\
\hline 120 & $82 \cdot I$ \\
\hline 150 & 129.3 \\
\hline 180 & $180^{\circ} 0$ \\
\hline
\end{tabular}

In the following constructions the maximum velocity of the meteoroid has been used. When the meteoroid's

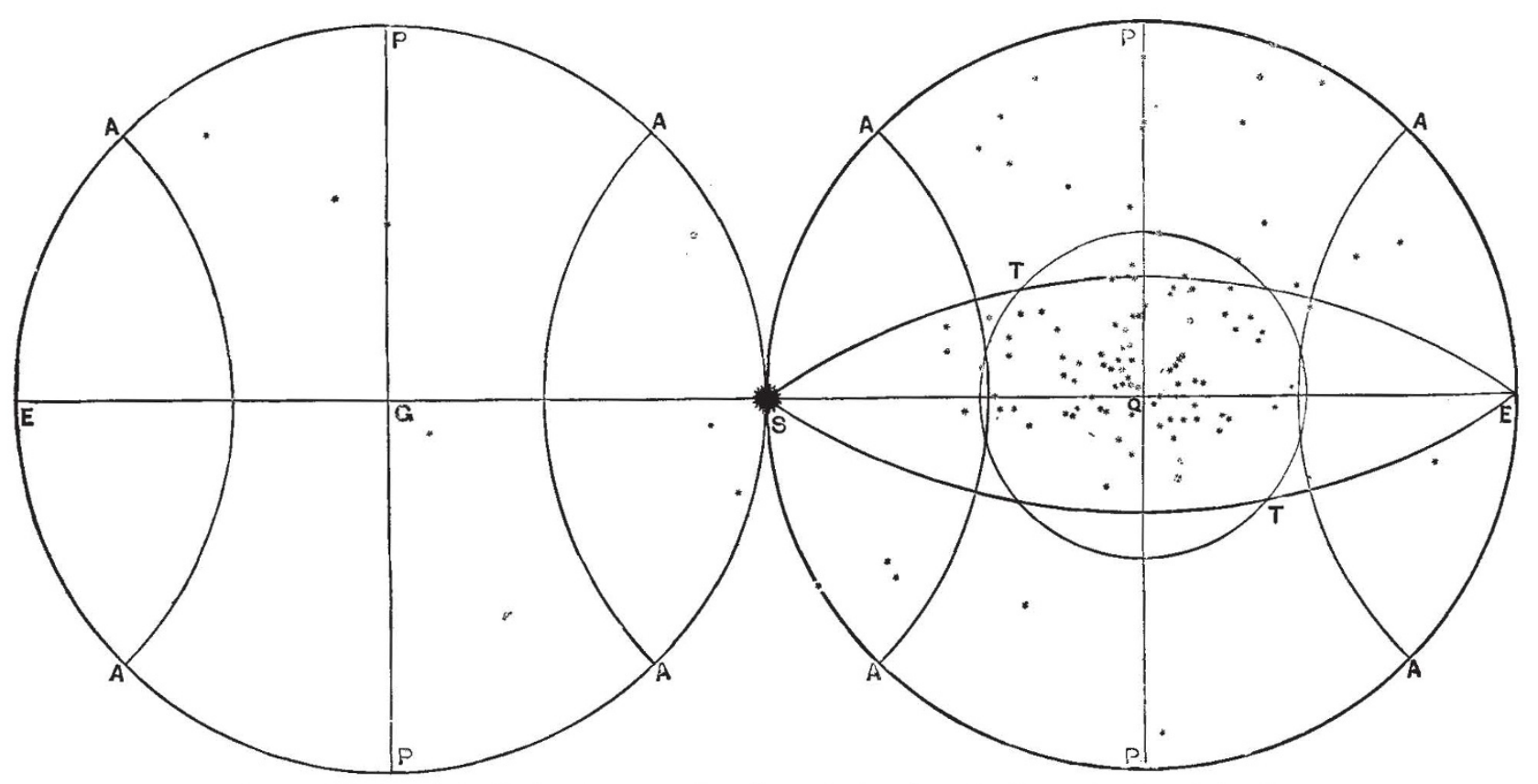

F1G. I. - Showing the distribution of 116 meteorite quits relatively to the sun's place and to the earth's quit.

relative quit is known as a point the absolute quit is at once constructed. If, however, we have an area within which the relative quit is probably located we may mark off with equal facility points on the boundaries of the area within which the absolute quit is probably located. If the former area is a circle the latter will be an oval. The centre of the circle does not correspond exactly to the centre of the oval, but by applying a correction to the table the centre of the oval absolute quit area can be directly constructed from the centre of the circular relative-quit area.

In Fig. I I have given in a single diagram constructed on a stereographic projection, the results for I I 6 stone-falls. The best determinations which the accounts admit of for the meteor's direction were first made out. Then the centre of the probable quit area in each case was assumed to be the actual quit. When only the quarter of the heavens from which the stones came is stated the centre of probable area was taken $20^{\circ}$ above the horizon. Interpreted thus, the stars in Fig. I represent the places of the
I 6 absolute quits relatively to the place of the sun, S, and to that of the earth's quit and goal, $Q$ and $G$.

Let us denote any one of these quits (or stars), by the letter $q$. The elements of the orbit in which the corresponding stone was formerly moving can be easily obtained from the projection. The earth's longitude on the day of fall is the longitude of the node. The angle $q \mathrm{SQ}$ is the inclination of the orbit to the ecliptic, and its amount is at once read off on the projection. The orbit has been assumed to have been a parabola. Hence, twice the complement of $q \mathrm{~S}$ was the angular distance of the stone from its perihelion. If $q \mathrm{~S}>90^{\circ}$, the perihelion had not been reached; if $q \mathrm{~S}<90$, the perihelion, had been passed. The peribelion distance was $\sin ^{2} \mathrm{QS}$. If, however, it be assumed that the orbit was a long ellipse of given major axis, the place of the absolute quit, $q$, moves somewhat nearer to $Q$ along the line $q Q \mathrm{Q}$, the angle in the plane of the orbit from perihelion was a little more than twice the complement of $q \mathrm{~S}$, and the perihelion distance somewhat less than $\sin ^{2} q \mathrm{~S}$. But all these 
quantities are easily computed in terms of the assumed major axis. With a semi-major axis as large as 5 the charge in Fig I would not be so considerable as to modify any conclusions we can deduce from the grouping of the stars.

The most noticeable fact revealed by the figure is the clustering of the stars about the point $Q$. All but seven of the I 16 meteor quits are in the $Q$ hemisphere ; that is, had orbits whose inclinations were less than $90^{\circ}$. One hundred and nine followed the earth, seven met it. Again the two lines STE are drawn to represent circles inclined $35^{\circ}$ to the ecliptic. More than two-thirds of the meteor quits lie between these two lines; hence, over two-thirds of the orbits were inclined less than $35^{\circ}$ to the ecliptic, the motion being direct.

It should be said that this clustering of the points near $Q$ is somewhat exaggerated in the figure by the nature of the stereographic projection. The scale of distances near $\mathrm{Q}$ differs from that near the circumference. But this does not affect the distribution between the hemispheres.
It has been assumed that certain centres of quit areas were themselves the quits. Can the condensation of the quits near $Q$ have been caused in any way by this assumption? Or, is it possible that general errors of observation, or inaccuracy of reporting, could have been the cause? To answer this question let us suppose that there had existed a law that led to condensation of the relative quits in any manner whatever. The effect of the errors of observing or reporting, and also the effect of the assumption above stated, would be toward scattering these relative quits over the heavens more equably, and thus masking the law. Then when the relative quits thus unduly scattered are reduced to absolute quits there might be as a result a tendency towards condensation near Q. If, however, we draw the circle TT, enclosing those absolute quits whose relative quits are in the hemisphere next $Q$, the general tendency of the errors in question would be towards equalizing the number of absolute quits within to those without the circle TT. Now, the number of stars is nearly twice as great within

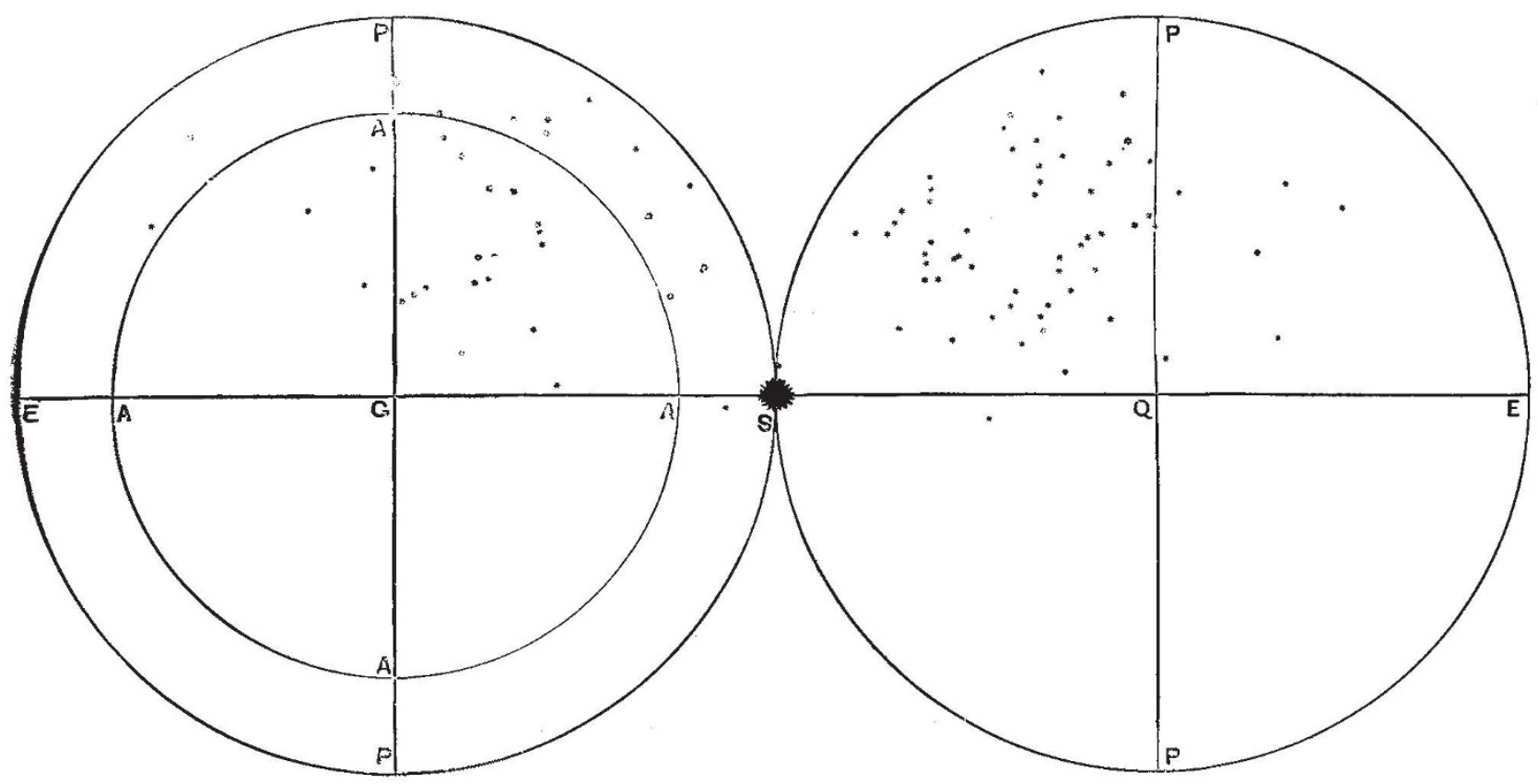

Fic. 2,-Showing relatively to the sun's place, the $z$ aniths for the time and place of 94 stone-falls.

as without the circle. The condensation about $Q$, shown in Fig. $\mathrm{r}$, exists therefore in spite of, and not in consequence of, these errors. With a good deal of confidence do I conclude that these 116 meteors were, as a class and with probably a very few exceptions, before coming into the air following the earth in its orbit about the sun.

Another fact of great interest is also shown by the grouping of the points in Fig. I. In general these stones did not go in their orbits very near to the sun. Assuming that the orbits were parabolas we have for all the stones whose perihelion distances were less than one-half, $\sin ^{2} q \mathrm{~S}<\frac{1}{2}$. If there be drawn circles, $\mathrm{AA}, \mathrm{AA}, 45^{\circ}$ from $\mathrm{S}$ and from $\mathrm{E}$, then will all the stones whose absolute quits were in the central zone, AP PA A A which is bounded by the circles A A, have perihelion distances greater than one-half and less than unity. Of these there are ro3 out of a total i16. If the same orbits are assumed to have had semi-major axes equal to 5 , then the circles A A would have to be drawn a fraction of one degree farther from $S$ and from $E$ to serve as the limiting curve to orbits whose perihelion distances exceed one-half.

It appears from Fig. I that these II 6 stones were, with a few exceptions, following the earth in their orbit about the sun. This could happen from either one or more of three possible causes:

Firstly, that nearly all the stones in the solar system are moving in direct orbits, very few in retrograde orbits ; -

Or, secondly, that stones moving in retrograde orbits for some reason, as for example their great relative velocity, may not have been able to pass through the air and to reach the ground in solid form ; -

Or, thirdly, that stones moving in such retrograde orbits, and coming through the air, may be falling while men sleep, or for some like reason may fail to be found. In other words, the effective cause may work above the air, in the air, or below the air.

Let us assume, as an hypothesis, that neither of the first two are the true causes. In that case we should have the stones moving in every direction as they cross the 
earth's orbit. There should be about as many orbits having retrograde motions as direct motions. Hence the absolute quits of all stones coming into and hence, by hypothesis, coming through the air, should be symmetrically distributed in their longitudes relative to the sun. At least there should be as many absolute quits in the G-hemisphere as in the $Q$ hemisphere (Fig. I). Take account now of the earth's motion and locate the relative quits. All these stones whose absolute quits lie outside of the circle T'T will have their relative quits in the G-hemisphere. Upon the hypothesis of parabolic orbits and of an equable distribution of the absolute quits over the celestial sphere the number of relative quits in the $\mathrm{G}$-hemisphere should be to those in the Q-hemisphere as $I+\cos \frac{\pi}{4}: 1-\cos \frac{\pi}{4}$, or as $17: 3$. The relative quits should then be viry much more numerous in the G-hemisphere than in the Q-hemisphere.

Furthermore, suppose that the heavens visible at a given time and place, are divided by a vertical circie into two halves; and suppose that this vertical circle is at right angles to the plane containing the zenith and the earth's quit and goal. That half of the visible heavens that lies towards the earth's goal may be called the goal-half, the other half may be called the quit-half of the visible heavens. In any given period there should evidently be, under the several hypotheses stated, many more stones coming into the air and reaching the ground directed from the goal-half than there should be directed from the quit-half of the risible heavens. Still further, since this proposition applies to any epoch whatever, we may apply it to I 16 periods covering the times of the I 16 stone-falls, that is, to the I 16 stone-falls themselves Many more of these should (under the hypotheses stated) have come from the goal-half than from the quit-half of the visible heavens.

If, then, the relative quit of each of these I 6 stones is supposed to be carried around in azimuth $180^{\circ}$, the altitude being unchanged, the II 6 distances from each new place of the quit to the earth's quit for the epoch of the fall should, in the average, be decidediy less than the corresponding i 6 distances from the actual relative quits to the earth's quit. This should hold true (under the hypo. theses stated) no matter what causes below the air may have occasioned the selection of the II 6 epochs. The fact that more persons are abroad in the evening hours from $6 \mathrm{~h}$. to Ioh. p.m., than in the corresponding morning hours, 2 h. to 6 h. a.m., may well cause that more stones should be secured in the evening than in the morning hours. In the evening hours the earth's quit is above the horizon ; in the morning hours the earth's goal. It might easily be that we should for this reason get more stones of direct than of retrograde motions. But the above criterion is entirely independent of any such principle of selection of the epochs. A change of the azimuth of the quits through $180^{\circ}$ should cause a larger number of them (under the hypotheses stated) to approach the earth's quit than to recede from it.

I have marked off upon the working sheets the position $180^{\circ}$ in azimuth from each of $I \mathrm{~s}$ relative quits, the altitude being unchanged, and measured the several distances from the earth s quit. (One fall, Nedagolla, was unavailable). The following is the result. In 44 cases the meteor's quit by the change approaches the earth's quit ; in 70 cases it approaches the earth's goal; in one it remains unchanged. That is, instead of a very large majority of the quits moving towards the earth's quit we have nearly two-thirds of them moving the other way. In the reversed position, moreover, we should have had 38 absolute quits in the G-hemisphere instead of 7 . These numbers show very decidedly that the hypotheses made above are not true. The principle of selection is not entirely below the air, and the numbers testify so markedly against that hypothesis that I feel warranted in adding that the cause is mainly either above the air, or in the air.

Between the first and second causes named the materials used for the present discussion do not furnish a positive critical test. But if, as I believe, the Stannern stone came from the south, we bave at least one instance of stones coming into the air with a velocity of nearly, or quite, 45 miles a second and reaching the ground in solid form. About twenty-five of the quits in Fig I imply velocities of not less than 25 miles a second on entering the air. Large velocities do not seem to be entirely fatal to the integrity of the meteorites. I believe that the first cause was the dominant one rather than the second, yet for a crucial test of the two causes, if one can be found, we must look to a class of facts other than those we hive been considering.

We are now in position to consider the other ninetyfour stone-falls. In Fig. 2, the construction of which is similar to that of Fig. I, the stars mark the zenith points for each time and place of the ninety-four falls. A grouping is at once noticeable. They are nearly all in the northern hemisphere, since the observing peoples live there. Those stars in the hemisphere of which $S$ is the pole, that is between the two lines P P and P P, are evidently daylight stone falls, since $S$ is above the horizon for each case. These constitute about seven-eighths of the whole number. The reason fo: this predominance is manifest. In the night men see the fireball or the train, whereas in the day the first intimation of the stone fall is usually the hearing of the detonation two or three minutes after the fireball has disappeared. Hence, daylight stone-falls are those whose directions are less likely to be observed, and these ninety-four falls are the ones of which the directions are unknown.

It will also be seen that there are nearly twice as many in the Q-hemisphere as in the G-hemisphere ; that is, there are nearly twice as many that fell when the earth's quit was above the horizon as there were when the earth's goal was above the horizon. In general, the former were afternoon stone-falls, the latter forenoon stone-falls. Now the habits of the urban population have not much to do with these daylight meteors, for the fireballs were not seen. The accounts come from the country, where the stones in general have fallen, and about as miny people are there abroad in the forenoon as in the afternoon If stones came to the ground as often from retrograde as from direct orbits we ought apparently to have had very many more zeniths in the $G$-hemisphere than in the Q-hemisphere. The contrary being the fact of experience we may reasonably say that the ninety-four stone-falls, about which we know comparatively little, seem decidedly to follow the same laws as the i 16 falls about which we know so much more.

This conclusion is greatly strengthened if we take account of the effect of the earth's attraction in carrying the meteor's quit toward the zenith. Any stone must be moving downward when it enters the air. But the earth's attraction must change the direction of its motion during the approach to the earth. Hence the region of the heavens from which a stone can approach the earth is not bounded by the actual horizon, but by a curve which may be treated as a depressed horizon. This depression of the horizon is far greater toward the quit than toward the the goal side of the horizon. The maximum depression for a stone moving in a parabolic orbit is about $17^{\circ}$. It hence follows that when the zenith is more than $73^{\circ}$ and less than $90^{\circ}$ from $G$, both the points $G$ and $Q$ are above the clepressed horizon, and therefore that the I4 falls whose zeniths are between these limits, that is, are between the circles A A and P E P S, Fig. 2, should be left out of the count. The corresponding region on the $\mathrm{Q}$ hemisphere is less than one degree in breadth, and con. tains one zenith point. We have left only 20 falls when 
the earth's goal alone was above the depressed horizon to be compared with 59 falls when the earth's quit alone was above the depressed horizon.

Of the 50 observet falls constituting the third group, of which the hour of fall is not stated, very few particulars other than the fact of fall are known. Although we are left without the pnwer of saying that they indicate the same law as the other 2 ro falls, we find at the same time no reason to suspect the contraty. It is not unreasonable to assume that the well observed stone-falls are good representatives of the whole group, and to affirm the three propositions with which I set out as true, in general, not only for the 210 stone-falls of the first two groups, but for the whole 260 stone falls which are represented by stones in our cabinets, and in which the stones were seen or known to fall.

It also seems a natural and proper corollary to these propositions (unless it shall appear that stones meeting the earth are destroyed in the air), that the larger meteorites moving in our solar system are allied much more closely with the group of comets of short period than with the comets whose orbits are nearly parabolic. All the known comets of shorter periods than 33 years move about the sun in direct orbits that have moderate inclinations to the Ecliptic. On the contrary, of the nearly parabolic cometic orbits that are known only a small proportion of the whole number have small inclinations with direct motion.

It also follows that in future reductions of these stone-fall observations it will be better to assume that the velocity of the stone in its orbit was not that velocity which corresponds to a parabolic orbit, but that which corresponds to the mean orbit of the comets of short period. The largeness of the perihelion distances has an evident bearing also upon the idea that these stones furm the fuel of the sun.

The presentation of the argument here made has been incomplete in that the details of the investigation of individual stone-falls have been entirely omitted. Some of the determinations of the paths are, I think, as complete as I can hope to make them. But others must be regarded as provisional, since 1 hope to secure respecting then additional data. I hope at some future time to give a complete discussion of all these observed stone-falls. In the past I have been greatly indebted to friends for aid in collecting accounts of the falls, and 1 heartily thank them therefore. I shall be very grateful also in the future for unpublished observations of the stone-falls, as well as for observations that have been so published as not to be likcly to have attracted attention. I bespeak the kindly aid of any who have made or have collected such observations.

\section{NOTES.}

A $\mathrm{r}$ the time of the Paris Exhibition in $\mathbf{r} 899$, several scientific congresses will assemble in the French capital-congresses of zoology, anthropology, physiology, electricity, dermatology, hygiene. The Rozuc Scicntifiguc expresses a hope that the great congress of electricity in $188 \mathrm{I}$ may be taken as a model for all these assemblies; that attempts will be made, as far as possible, to establish uniformity in scientific nomenclature ; and that men of science in other countries will not allow themselves to be deterred by international jealousies from being adequately represented at meetings whose proceedings will relate to matters of universal interest.

At the next meeting of the British Association there will be a discussion in Section D on the vexed question of the formation of coral reefs. The discussion will be opened by Dr. Sydney J. Hickson.
ON Tuesday evening Mr. W. II. Smith, speaking of the measures with which it would be impossible to deal during the present Session, announced that the Government had decided to drop the Technical Instruction Bill. He deeply regretted that this was necessary, "but perhaps," he addled, "there may not be much loss of time, as the Royal Commission on Elemen ary Education will report shortly on the whole question, and it will be interesting and convenient to the House to have that report before it before attempting to legislate on the subject."

A Conference of the Executive Committee of the National Association for the Prómotion of Technical Education and representatives of branches and co-operating associations was helcl last Saturday afiernoon at the Society of Arts. Afterwards the first annual meeting of the Association was held. Lord Hartington presided, and delivered an able and interesting speech, showing how the establishment of a proper system of technical instruction has been renclered a solutely necessary by the conditions of modern industrial development.

THE anniversary meeting of the Sanitary Tastitute of Great Britain will be held to-day at 3 p.m. The chair will be taken by Mr. Edwin Chadwick, C.B., who will present the medals and certificates awarderl to the exhibitors at the exhibition held at Bolton. Dr. B. W. Richardson, F.R.S., will deliver an address, entitled, "The Storage of Life a: a Sanitary Stury."

ON Thursclay, the 5 th inst., Prof. Sickes distributed the prizes to the students at the Medical School, St. Thomas's Hospital. In addressing the students he said that he need not $r e m i n d t h+m$ that diligence was the great road to success, and urged that it was a duty to work for our fellow-creatures as well as ourselves. He thought that the twi, nothlest professions were those, one of which assisted in the rectification of man's character and the other in alleviating the results of clisease. In the exercise of the medical profession our best feelings were, he thought, called forth. The best foundation was a general liberal education, and although those branches of science which bear directly on medicine might be separated from their practical application, they were in themselves most interesting, and, when studied for their own sakes, were excellent mental training. $\mathrm{He}$ was glad to hear from I)r. Ord that St. Thomas's students were successful in athletics, as the cups exhibited testifred. In the necessarily sedentary life of a medical student exercise and relaxation should not be reglected, and students did well to study the use of their muscles in athletic pursuits, Sir Jobn Simon, on behalf of the Governors of the Hospital, thanked Prof. Stokes for distributing the prizes, and referred to the high position attained by Prof. Stokes, who, as President of the Royal Society, and representative in Parliament of the Univer. sity of Sir Jsaac Newton, might be said to have gained the best possible prize, but binted that the happiness of life consisted in its endeavours rather than in its mizes. He concluded by allud ing to the retirement of Dr. Ord, whose services as Dean of the Medical School during the past twclve years had been, he felt sure, much appreciated by the Governors of the Hospital, hy the medical and surgical staff, and by the students.

THE French Minister of Public Instruction has authorized the following scientific missions:-M. Georges Martin is entrusted with a mission to Sweden and Norway, to study the different educational questions; M. Henry Meyners d'Estrey is sent to explore the mountainous districts of Scanlinavia, and to study certain questions connected with ethnography and anthropology; M. Gaston Angelvy, civil engineer, goes in explore the tract of country between Lake Nyassa and the coast of the Indian Ocean, and to visit more paricularly the basin of the river Rriyaurva.

THE Musée Guimet in Paris, which contains specimens of a great number of objects used in religious ceremonies, was 